\title{
Staged ligation of large portosystemic collaterals in living donor liver transplantation using a small-for-size graft
}

\author{
Chao-Long Chen ${ }^{1}$, Chee-Chien Yong ${ }^{1}$, Jeffrey Samuel Co ${ }^{1}$, Chih-Yi Chen ${ }^{1}$, Aldwin Ong ${ }^{1}$, Chih-Che Lin ${ }^{1}$, \\ Yu-Fan Cheng ${ }^{2}$
}

${ }^{1}$ Liver Transplantation Center, Department of Surgery, ${ }^{2}$ Diagnostic Radiology, Kaohsiung Chang Gung Memorial Hospital, Kaohsiung

Correspondence to: Chao-Long Chen, MD, PhD (Hon). Liver Transplantation Center, Department of Surgery, Kaohsiung Chang Gung Memorial Hospital, 123 Ta-Pei Road, Niao-Sung, Kaohsiung 833. Email: clchen@cgmh.org.tw.

Provenance and Peer Review: This article was not commissioned by the editorial office. The article was sent for external peer review.

Submitted Feb 27, 2020. Accepted for publication Apr 13, 2020.

doi: $10.21037 / \mathrm{hbsn}-20-330$

View this article at: http://dx.doi.org/10.21037/hbsn-20-330

The success of using a partial graft for liver transplantation depends highly on portal venous flow as it is the primary determinant of graft regeneration. Portosystemic collaterals (PSCs) are not uncommon, with an incidence reported to be as high as $40 \%$ amongst liver transplant candidates (1). These shunts have been implicated in portal flow steal, a phenomenon known to result in graft hypoperfusion, dysfunction and in some cases, graft failure. In light of this, several authors have recommended routine ligation of significant PSCs during living donor liver transplantation (LDLT) in order to avoid portal flow steal syndrome $(2-4)$. On the other hand, when single stage ligation of PSCs is performed during primary LDLT in patients receiving small-for-size grafts, the recipient will be at risk of developing early graft dysfunction and/or small-forsize syndrome as a result of portal hyperperfusion. We propose a novel strategy for small-for-size grafts where we intentionally leave large PSCs open during primary LDLT to avoid small-for-size syndrome, followed by staged ligation of large PSCs to prevent portal flow steal syndrome after sufficient graft regeneration.

A 53-year-old Malaysian lady with primary biliary cirrhosis and repeated variceal bleeding was referred for pre-transplant evaluation. The patient had hyperbilirubinemia, hypoalbuminemia, coagulopathy and pancytopenia (MELD:15, CTP:10, UNOS:2B). Her CTangiogram showed liver cirrhosis, splenomegaly, portal vein (PV) thrombosis (Yerdel grade 1) and two large PSCs-the coronary vein, $10.9 \mathrm{~mm}$, and a gastrorenal shunt, $11.6 \mathrm{~mm}$ (Figure 1A,B). The donor, who was the patient's husband, was $\mathrm{ABO}$-compatible, with a marginal left lobe graft volume to recipient standard liver volume (SLV) ratio of $35 \%$ by CT volumetry estimate. The patient subsequently underwent LDLT with the left lobe graft that included the caudate lobe and the middle hepatic vein. The actual graft was, however, smaller than the CT volumetric estimate, with a weight of only $284 \mathrm{~g}$ (31\% SLV, GRWR $0.73 \%)$. The PV was reconstructed following eversion thromboendovenectomy. After reperfusion, the portal pressure gradient was only $7 \mathrm{mmHg}$ (portal venous pressure $15 \mathrm{mmHg}$ minus central venous pressure $8 \mathrm{mmHg}$ ), while PV velocity and portal flow volume by Doppler ultrasound were $43.8 \mathrm{~cm} / \mathrm{sec}$ and $602 \mathrm{~mL} / \mathrm{min}(202 \mathrm{~mL} / 100 \mathrm{~g} / \mathrm{min})$ respectively.

In order to avoid early graft dysfunction and/or smallfor-size syndrome, the large PSCs were intentionally left patent, with a plan for subsequent staged ligation to prevent future portal flow steal syndrome. This was likewise particularly decided for the patient as she was from overseas and close follow-up with frequent Doppler ultrasound and/ or CT imaging was logistically not feasible.

The recipient's post-transplant course was unremarkable and surveillance CT angiogram at one month after LDLT showed adequate regeneration to more than double the original graft volume $(634 \mathrm{~mL})$ with notable optimal vascularity. The PSCs at that time were still prominent, with measurement of $8.2 \mathrm{~mm}$ for the coronary vein and $11 \mathrm{~mm}$ for the gastrorenal shunt (Figure 1C,D). The patient subsequently underwent the planned open surgical ligation of the PSCs with intra-operative cine-portogram guidance 

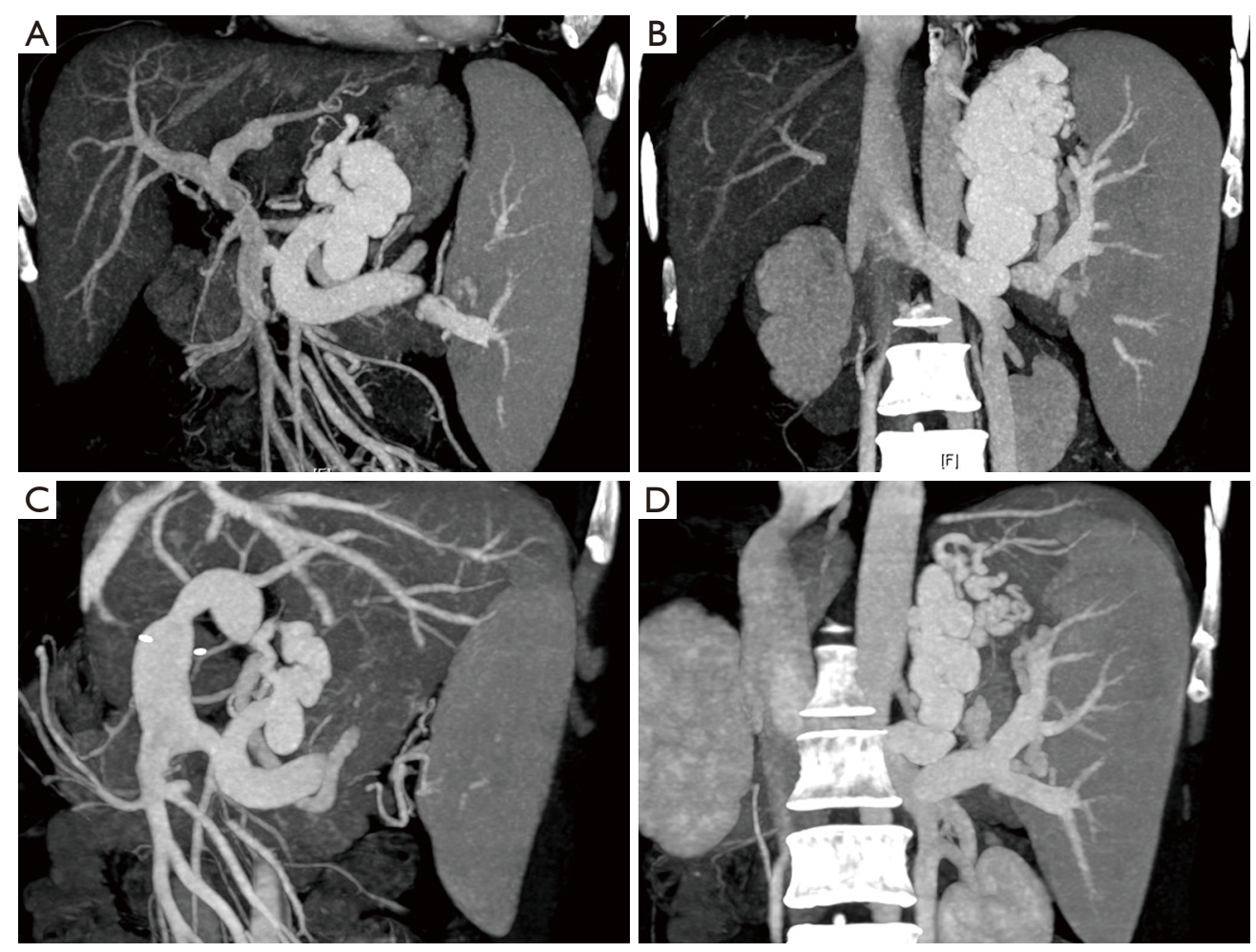

Figure 1 Pre-transplant CTA showing large coronary vein $10.9 \mathrm{~mm}$ (A), and gastrorenal shunt $11.6 \mathrm{~mm}$ (B). One month after LDLT, the coronary vein was still prominent $8.2 \mathrm{~mm}(\mathrm{C})$, and gastrorenal shunt $11 \mathrm{~mm}(\mathrm{D})$.

and portal pressure monitoring. Although test clamping of the PSCs increased the portal pressure gradient from 11 to $16 \mathrm{mmHg}$, we still proceeded with ligation of PSCs as the regenerated graft was by then already deemed adequate to tolerate a hyperdynamic portal flow state. The recipient recovered well and was able to return to Malaysia with perfect liver function.

In liver transplant recipients with large PSCs, Ikegami et al. suggested shunt ligation to prevent portal flow steal, and synchronous splenectomy for PV decompression (4). In the case of this patient with a small-for-size graft, the portal pressure gradient was only $7 \mathrm{mmHg}$ (portal venous pressure $15 \mathrm{mmHg}$ minus central venous pressure $8 \mathrm{mmHg}$ ) after reperfusion; PV velocity and portal flow volume by Doppler ultrasound were $43.8 \mathrm{~cm} / \mathrm{sec}$ and $602 \mathrm{~mL} / \mathrm{min}$ $(202 \mathrm{~mL} / 100 \mathrm{~g} / \mathrm{min}$ ) respectively. With these values, portal inflow modulation was not indicated with either splenic artery ligation or splenectomy. Instead, a decision was made for staged surgical ligation of PSCs in order to allow for initial graft regeneration prior to subsequent PSC ligation to prevent future risk for portal flow steal syndrome. This strategy was particularly appropriate for this patient who was from overseas and whose close follow-up with Doppler ultrasound and/or CT imaging monitoring was untenable.

Portal flow steal is not uncommon in LDLT because partial liver grafts undergo rapid regeneration in order to meet the metabolic demands of the recipient (5). Although the portal flow remained hepatopetal at 1 month after LDLT in this patient, we have adequate knowledge that an increase in intra-hepatic resistance to portal flow and a decrease in graft compliance-such as during rapid graft regeneration, or conditions including graft rejection, dysfunction, and cholangitis - predisposes already shrunken PSCs to re-open. Consequentially, there would be a reduction in portal perfusion that may potentially lead to a pathophysiologic portal flow steal and subsequent secondary graft damage, that may occur acutely or over a period of years after LDLT. The staged operation was therefore intended to prevent delayed portal flow steal syndrome, particularly for this and similar other patients who will be foreseen to encounter logistical challenges in the course of their short-interval follow-up.

In our novel strategy for recipients with large PSCs receiving small-for-size grafts, we intentionally leave large 
PSCs open during primary LDLT to avoid small-forsize syndrome, and follow this up with staged or interval ligation of the remaining identified large PSCs in order to prevent portal flow steal syndrome after sufficient graft regeneration. By using this technique, we are also able to avoid post-splenectomy complications, in particular, splenic and subsequent $\mathrm{PV}$ thrombosis in patients with pretransplant $\mathrm{PV}$ thrombosis.

In conclusion, staged-ligation of large PSCs in recipients receiving small-for-size grafts, may be a feasible consideration. This strategy of delaying closure of large PSCs may considerably reduce the risk for both small-forsize syndrome and portal flow steal syndrome; at the same time, outright splenectomy during primary LDLT and its potential risks and complications may be avoided.

\section{Acknowledgments}

Funding: None.

\section{Footnote}

Conflicts of Interest: All authors have completed the ICMJE uniform disclosure form (available at http://dx.doi. org/10.21037/hbsn-20-330). CLC serves as an unpaid editorial board member of Hepatobiliary Surgery and Nutrition. The other authors have no conflicts of interest to declare.

Ethical Statement: The authors are accountable for all aspects of the work in ensuring that questions related to the accuracy or integrity of any part of the work are

Cite this article as: Chen CL, Yong CC, Co JS, Chen CY, Ong A, Lin CC, Cheng YF. Staged ligation of large portosystemic collaterals in living donor liver transplantation using a smallfor-size graft. HepatoBiliary Surg Nutr 2020;9(4):555-557. doi: 10.21037/hbsn-20-330 appropriately investigated and resolved.

Open Access Statement: This is an Open Access article distributed in accordance with the Creative Commons Attribution-NonCommercial-NoDerivs 4.0 International License (CC BY-NC-ND 4.0), which permits the noncommercial replication and distribution of the article with the strict proviso that no changes or edits are made and the original work is properly cited (including links to both the formal publication through the relevant DOI and the license). See: https://creativecommons.org/licenses/by-nc-nd/4.0/.

\section{References}

1. Reddy MS, Rela M. Portosystemic collaterals in living donor liver transplantation: What is all the fuss about? Liver Transpl 2017;23:537-44.

2. Lee SG, Moon DB, Ahn CS, et al. Ligation of left renal vein for large spontaneous splenorenal shunt to prevent portal flow steal in adult living donor liver transplantation. Transpl Int 2007;20:45-50.

3. Golse N, Bucur PO, Faitot F, et al. Spontaneous splenorenal shunt in liver transplantation: Results of left renal vein ligation versus renoportal anastomosis. Transplantation 2015;99:2576-85.

4. Ikegami T, Shirabe K, Nakagawara H, et al. Obstructing spontaneous major shunt vessels is mandatory to keep adequate portal inflow in living-donor liver transplantation. Transplantation 2013;95:1270-7.

5. KitaY, Harihara Y, Sano K, et al. Reversible hepatofugal portal flow after liver transplantation using a small-for-size graft from a living donor. Transpl Int 2001;14:217-22. 